\title{
APLIKASI FILLING REKAM MEDIS MENGGUNAKAN METODE ALGORITMA TURBO BOYER MOORE
}

\author{
Beni Harzani ${ }^{1}$, Diana $^{* 2}$ \\ Program Studi Teknik Informatika Universitas Bina Darma Palembag \\ JL. A. Yani No.03 Plaju, Palembang, 30264 \\ 'bennyharzani57@gmail.com, ${ }^{2}$ diana@binadarma.ac.id
}

\begin{abstract}
Puskesmas Nagaswidak merupakan salah satu pusat kesehatan masyarakat yang cukup besar dan memiliki fasilitas yang lengkap. Namun permasalahan yang sering dihadapi para petugas dipuskesmas yakni sistem pengolahan data rekam medis yang masih manual sehingga menyebabkan adanya penumpukan data berkas rekam medis pasien, selain itu pasien yang telah di cek sebelumnya dan kehilangan nomor medrek (medical record) mereka, sangat menyulitkan petugas untuk mencari nya kembali, sehingga petugas membuatkan data rekam medis yang baru. Untuk mengatasi masalah tersebut, maka dibuatlah Aplikasi Filling Rekam Medis pada Puskesmas Nagaswidak yang mencakup pengolahan rekam medis, data pasien, data obat, data tindakan, data dokter, dan login admin. Agar masalah pencarian data tidak sulit maka diterapkan metode algoritma turbo boyer moore yang diharapkan nantinya dapat mempermudah pencarian data pasien dalam aplikasi filling rekam medis. Berdasarkan hasil uji coba Algoritma Boyer Moore berhasil di implementasikan untuk pencarian di awal kata, tengah kata, dan akhir kata. Dan tingkat kemudahan dan tingkat kegunaan aplikasi rekam medis dengan menggunakan algoritma Boyer Moore didapatkan hasil bahwa tingkat kemudahan yaitu $80 \%$ dan tingkat kegunaan $100 \%$.
\end{abstract}

\section{Kata Kunci-Aplikasi, Rekam Medis, Algoritma Turbo Boyer Moore}

Abstract- Nagaswidak Health Center is one of the community health centers that is quite large and has complete facilities. But the problem that is often faced by officers in the puskesmas is the medical record data processing system which is still manual, causing the accumulation of patient medical record file data, in addition to patients who have been checked before and lost their medical records, it is very difficult for officers to find back, so the officer made a new medical record data. To overcome this problem, a Medical Records Filling Application was made at the Nagaswidak Health Center which includes the processing of medical records, patient data, drug data, action data, doctor data, and admin logins. So that the data search problem is not difficult, the turbo boyer moore algorithm method is applied which is expected to later be able to facilitate the search for patient data in the medical record filling application. Based on the test results Boyer Moore's Algorithm successfully applied to search for the beginning of a word, middle word, and final word. And the level of ease and usefulness of medical records application using Boyer Moore's algorithm obtained results that the level of ease is $80 \%$ and $100 \%$ usability rate.

Keywords-Application, Medical Record, Turbo Boyer Moore Algorithm

\section{PENDAHULUAN}

Pembuatan aplikasi rekam medis dapat mempermudah petugas filling untuk mengontrol dan mengendalikan dokumen rekam medis, meningkatkan efektivitas komunikasi antar petugas medis, selai itu tidak memerlukan ruang penyimpanan yang besar dan juga memberikan informasi atau pengingat kepada petugas rekam medis untuk menindaklanjuti pasien. Permasalahan yang sering dihadapi para petugas di puskesmas yakni sistem pengolahan data rekam medis yang masih manual sehingga menyebabkan adanya penumpukan data rekam medis pasien, selain itu pasien yang telah dicek sebelumnya dan kehilangan nomor medrek (medical record), sangat menyulitkan petugas untuk mencarinya kembali, sehingga petugas membuatkan data rekam medis baru yang berdampak dalam penyimpanan ruang yang besar. Pencarian data dalam jumlah data yang besar mengakibatkan waktu yang lama sehingga agar lebih cepat dan akurat maka diterapkan suatu teknik Turbo Boyer Moore.

Algoritma Turbo Boyer Moore adalah algoritma pencarian string yang paling efektif saat ini. Algoritma Turbo Boyer Moore diperkenalkan oleh Bob Boyer dan J.S Moore pada tahun 1977. Menurut [1], pada algoritma ini pencocokan kata dimulai dari karakter terakhir kata kunci menuju karakter awal. Jika terjadi perbedaan antara karakter terakhir kata kunci dengan 
kata yang dicocokan maka karakter-karakter dalam potongan kata yang dicocokan tadi akan diperiksa satu per satu . Algoritma ini memiliki banyak kelebihan. Dalam tulisannya [2] menyatakan bahwa algoritma turbo boyermoore mempunyai keunggulan dalam

Page|260 waktu menemukan pattern yang akan dicari dalam ukuran file yang lebih besar.

Penelitian tentang penerapan algoritma Boyer Moore juga telah banyak dilakukan oleh [3] bahwa proses pencarian istilah pada aplikasi kamus kedokteran dimana pencarian kata dengan algoritma Boyer Moore berhasil dilakukan dengan persentase sebesar $100 \%$. Penelitian berikutnya dilakukan oleh [4] dimana algoritma Boyer Moore mempunyai keunggulan dalam waktu menemukan pattern yang akan dicari dalam ukuran file yang lebih besar, dengan file size 4.625 byte dengan varian keyword berbeda. Sedangkan dalam penelitian [5] dengan adanya algoritma Turbo Boyer Moore pada pencarian judul maka proses yang dilakukan lebih efektif, cepat dan mudah. Dalam tulisannya [6] proses deteksi kata bahasa inggris dengan algoritma Boyer Moore jumlah kata asing yang terdeteksi sudah sesuai dengan kata yang ada dalam database, tetapi semakin banyak jumlah kata yang ada pada teks maka semakin bertambah waktu yang di butuhkan dalam melakukan pencarian. Penelitian berikutnya dilakukan oleh [7] algoritma Boyer Moore terbukti sebagai metode pencocokan string yang sangat efisien. Perbandingan hasil dan waktu sangat berimbang dan sangat sesuai untuk diterapkan pada proses pencarian string. Penelitian selanjutnya dilakukan oleh [8] bahwa implementasi algoritma Boyer Moore berhasil dilakukan dari dengan cara memasukan kata pada bidang teks yang dicari dengan rentang waktu terendah 126 dengan kata (a,b) sampai yang tertinggi 165 dengan masukan (a,b,o,r,t,u,s). metode ini menghasilkan waktu pengiriman hasil kata dengan 0 $\mathrm{ms} / \mathrm{sec}$.

\section{LANDASAN TEORI}

\section{A. Rekam Medis}

Menurut [9] rekam medis adalah keterangan yang tertulis maupun yang terekam tentanng identitas, anamneses, pemeriksaan fisik, laboratorium, diagnose serta segala pelayanan dan tindakan yang diberikan kepada pasien, dan pengobatan yang dirawat inap, rawat jalan maupun yang mendapatkan pelayanan gawat darurat . Menurut PREMENKES RI Nomor 269 Tahun 2008 bab 1 pasal 1 menyatakan rekam medis adalah berkas yang berisikan catatan dan dokumen tentang identitas pasien, pemeriksaan, pengobatan, tindakan dan pelayanan lain yang telah diberikan kepada pasien .

\section{B. Algoritma Turbo Boyer Moore}

[8] menuliskan bahwa Algoritma Turbo Boyer Moore merupakan pengembangan dari algoritma boyer moore. Algoritma ini tidak memerlukan preprocessing tambahan dan hanya membutuhkan ruang ekstra konstan sehubungan dengan algoritma boyer moore terdahulu. Algoritma turbo boyer moore adalah sebuah algoritma pencocokan pola tertentu terhadap suatu kalimat atau paragraph. Algoritma ini merupakan varian dari algoritma boyer moore yang memungkinkan terjadinya lompatan melewati segmen yang tidak memerlukan preprocessing tambahan dengan kecepatan yang baik .

Menurut [10] dalam bukunya Handbook of Exact String Matching Algorithm mengatakan algoritma Boyer Moore adalah algoritma yang paling efesien pada aplikasi umum. Algoritma boyer moore bekerja dengan memulai pencocokan pattern dari kanan bukan dari kiri. Dengan memulai pencocokan karakter dari kanan, maka akan lebih banyak informasi yang di dapat . Menurut [11], Algoritma turbo boyer moore mengambil metoe pencarian string boyer moore yaitu good suffix dan bad character suffix. Akan tetapi algoritma turbo boyer moore berbeda dengan algoritma boyer moore, algoritma ini memungkinkan terjadinya lompatan melewati segmen mengingat faktor dari teks yang cocok dengan akhiran dari pattern selama attempt terakhir sehingga memanfaatkan teknik turbo shift . Turbo shift dapat terjadi jika terdapat substring dari pattern yang sama dengan substring pada teks yang sudah diperiksa sebelumnya.

\section{Langkah-langkah Algoritma Boyer Moore}

Untuk menjelaskan konsep dari good suffix dan bad character shift diperlukan contoh kasus, seperti ketidak cocokan ditengah pencocokan karakter pada teks dan pattern. Karakter pattern $x[i]=a$ tidak cocok dengan karakter teks $y[i+j]=b$ saat pencocokan pada posisi $j$. Maka $x[i+1 . . m-1]=y[i+j+1 . . j+m-1]=u$ dan $x[i] \neq y[i+j]$

1) Good Suffix shift adalah pergeseran yang dibutuhkan dari $x[i]=a$ ke karakter lain yang letaknya lebih kiri dari $x[i]$ dan terletak disebelah kiri segmen $z$. 


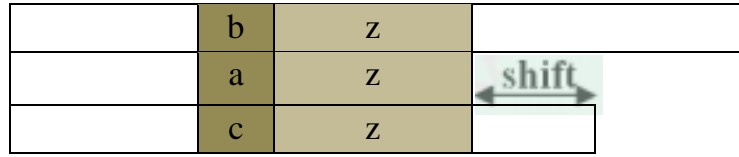

Page | 261

2) Jika tidak ada segmen yang sama dengan $z$, makan di cari $z$ yang merupakan suffix terpanjang $z$.

\begin{tabular}{|l|l|l|l|}
\hline & $b$ & $z$ & \\
\hline & $a$ & $z$ & shift \\
\hline
\end{tabular}

3) Bad character shift adalah karakter pada teks yang tidak cocok dengan karakter pattern. Jika bad character $y[i+j]$ terdapat pada pattern di posisi terkanan $k$ yang lebih kiri dari $x$ [i] maka pattern digeser ke kanan sejauh $i-k$.

\begin{tabular}{|c|c|c|c|}
\hline \multicolumn{1}{|c|}{} & $\mathrm{b}$ & $\mathrm{Z}$ & \\
\hline & $\mathrm{a}$ & $\mathrm{Z}$ & shift \\
\hline & $\mathrm{b}$ & \multicolumn{2}{|c|}{ Contains no b } \\
\hline
\end{tabular}

4) Jika bad character shift $y[i+j]$ tidak ada pattern sama sekali, maka pattern digeser ke kanan sejauh $i$.

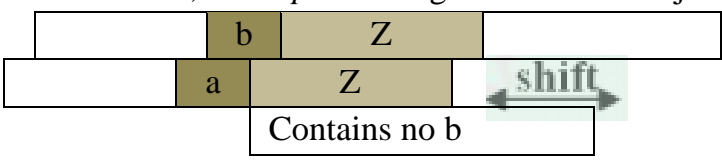

5) Jika bad character shift $y[i+j]$ terdapat pattern di posisi terkanan $k$ yang lebih kanan dari $x[i]$ maka pattern seharusnya digeser sejauh $i-k$ yang hasilnya negative (pattern digeser kembali ke kiri).

\section{METODELOGI PENELITIAN}

\section{A. Tempat Penelitian}

Penelitian ini dilakukan di Puskesmas Nagaswidak yang beralamat di Jalan A. Yani Lorong Gumay Gg. Bangdes RT. 22, Kelurahan 14 Ulu, Kecamatan Seberang Ulu II, Kota Palembang, 30264.

\section{B. Data Penelitian}

Dalam mengumpulkan data, peneliti menggunakan metode wawancara dan observasi. Dimana peneliti bertanya dan melihat langsung kepada pihak yang bersangkutan agar dapat memberikan informasi yang dibutuhkan berupa data data obat, data dokter dan data rekam medis pasien di puskesmas Nagaswidak Palembang. Data obat yang digunakan ada 30 jenis obat, data dokter terdiri dari 10 dokter umum dan 15 dokter spesialis, data rekam medis pasien sebanyak 300 data.

Data obat terdiri dari 5 field yakni No, Kode Obat, Nama Obat, Harga, dan Kategori. Data dokter terdiri dari 7 field yaitu Id dokter, NamaDokter, Spesialisasi, Alamat, Kota, Email, dan Kontak. Data rekam medis pasien terdiri dari 9 field yaitu Id, Nama Pasien, Alamat, Jenis Kelamin, Umur, No Ktp, Jenis Peserta, Tanggal Daftar, dan Status Berobat.

\section{Langkah Penelitian}

Langkah-langkah pada penelitian ini adalah :

1) Pengumpulan data

Pengumpulan data dilakukan dengan melakukan observasi pada bagian petugas filling, observasi ini untuk mengetahui tatacara proses bisnis rekam medis pada saat ini.

2) Analisis Kebutuhan Aplikasi

Pada tahap ini dilakukan simulasi perhitungan algoritma Boyer Moore. Analisis kebutuhan sistem meliputi analisis kebutuhan fungsional dan analisis kebutuhan non fungsional.

3) Perancangan Aplikasi

Perancangan aplikasi meliputi perancangan arsitektur, perancangan masukan, proses dan keluran aplikasi.

4) Implementasi Aplikasi

Pada tahap ini dilakukan pengkodean.

5) Pengujian Aplikasi

Pengujian dilakukan dengan melakukan 5 kali uji coba variasi kata kunci untuk melakukan pencarian diawal kata, tengah kata dan akhir kata. Dan menyebarkan kuisioner kepada 5 petugas filling untuk mengetahui tingkat kemudahan dan tingkat kegunaan aplikasi. Kuisioner dibuat dalam skala ya dan tidak.

\section{IV.HASIL DAN PEMBAHASAN}

\section{A. Analisis Kebutuhan Aplikasi}

Analisis kebutuhan fungsional aplikasi rekam medis pasien adalah sebagai berikut :

1) Form Login, untuk menentukan siapa saja yang boleh menggunakan atau mengakses data.

2) Form obat, untuk menambah, mengedit, dan menghapus daftar obat.

3) Form Pasien, untuk melihat data pasien yang ada serta untuk menambah, mengedit dan menghapus.

4) Form Dokter, berfungsi untuk menambah, mengedit dan menghapus.

5) Form Rekam Medis, meliputi fungsi tambah, mengedit dan menghapus.

6) Form Riwayat Kunjungan, berfungsi sebagai data kunjungan pasien selama berobat.

7) Form Stok Obat, untuk melihat daftar stok obat apa saja yang masih ada dan yang telah habis.

8) Form Laporan, memberikan informasi berapa banyak pasien yang terdata selama rekam medik yang telah dikumpulkan sebelumnya.

9) Form Data Akun, berfungsi untuk menambahkan pengguna aplikasi dalam mengakses data. 
10)Form keluar, berfungsi untuk keluar atau logout dari aplikasi rekam medis.

Analisis kebutuhan non fungsional untuk membangun aplikasi rekam medis pasien adalah sebagai berikut :

1) Perangkat keras terdiri dari :

a) Laptop dengan processor Intel Core i3 $2.7 \mathrm{GHz}$

b) Memory (RAM) 4GB

c) Disk Space 500GB

2) Perangkat Lunak terdiri dari :

a) Operation System Windows 7 Ultimate

b) Apache 2.0 sebagai web server

c) Adobe Dreamweaver CS6 digunakan untuk pembuatan tampilan antarmuka (UI)

d) $P H P$, Menurut [12] $P H P$ adalah pemograman interpreter yaitu proses penerjemahan baris kode sumber menjadi kode mesin yang dimengerti computer secara langsung pada saat baris kode dijalankan. PHP disebut sebagai pemoraman Server Side Progrmming, hal ini dikarenakan seluruh prosesnya dijalankan pada server.

e) MySQL, MySQL adalah sebuah perangkat lunak pembuat database yang bersifat terbuka atau open source dan berjalan disemua platform baik Linux maupun Msistem operasi windows, MySQL merupakan program pengakses database yang bersifat network sehingga dapat digunakan untuk aplikasi Multi User [13].

f) UML, Menurut [14] UML (Unified Modeling Language) adalah 'bahasa' pemodelan untuk sistem atau perangkat lunak yang berpradigma 'berorientasi objek'. Pemodelan (modeling) sesungguhnya digunakan untuk penyederhanaan permasalahan-permasalahn yang kompleks sedemikisn rupa sehingga lebih mudah dipelajari dan dipahami.

\section{B. Hasil Perancangan Aplikasi}

Perancangan aplikasi digambarkan dalam bentuk use case diagram, activity diagram dan class diagram.

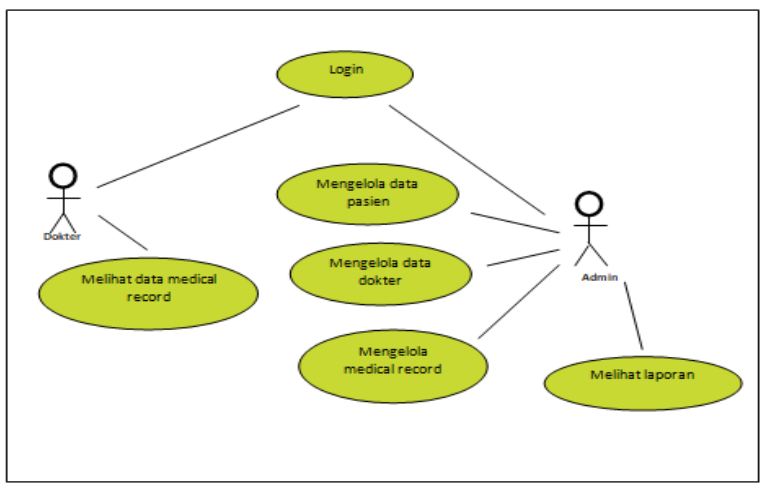

Gbr 1. Use Case Diagram
Gambar diatas merupakan proses dari perangkat lunak rekam medis, yang mengelolah data pasien, data dokter, dan data medical record adalah admin puskesmas Nagaswidak

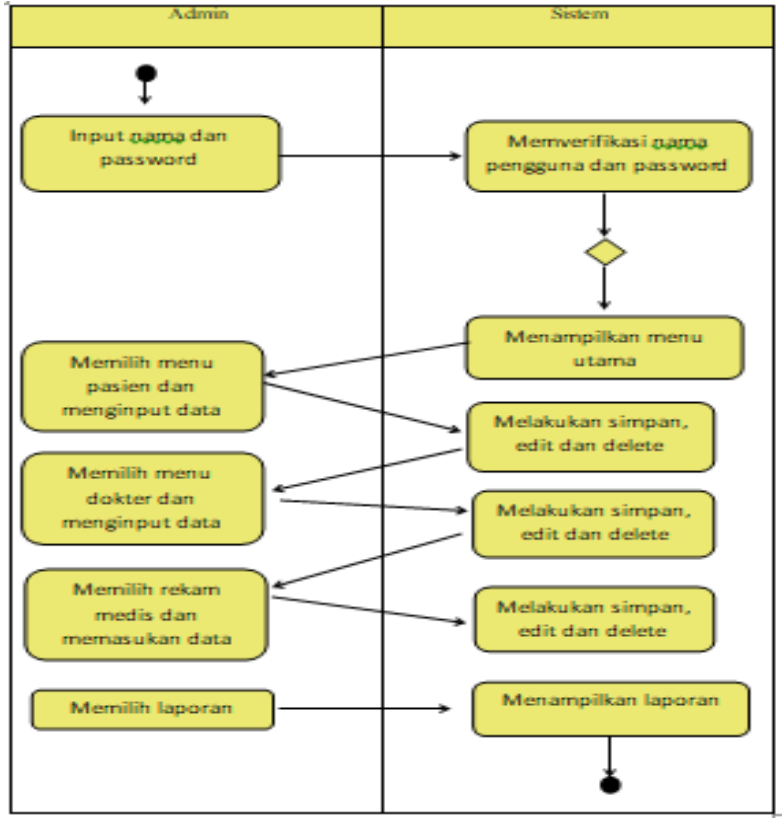

Gbr 2. Activity Diagram Admin

Diagram aktifitas admin ini berfungsi untuk menggambarkan proses interaksi admin dalam system, mulai dari mengelola data pengguna, data pasien, data dokter dan data medical record

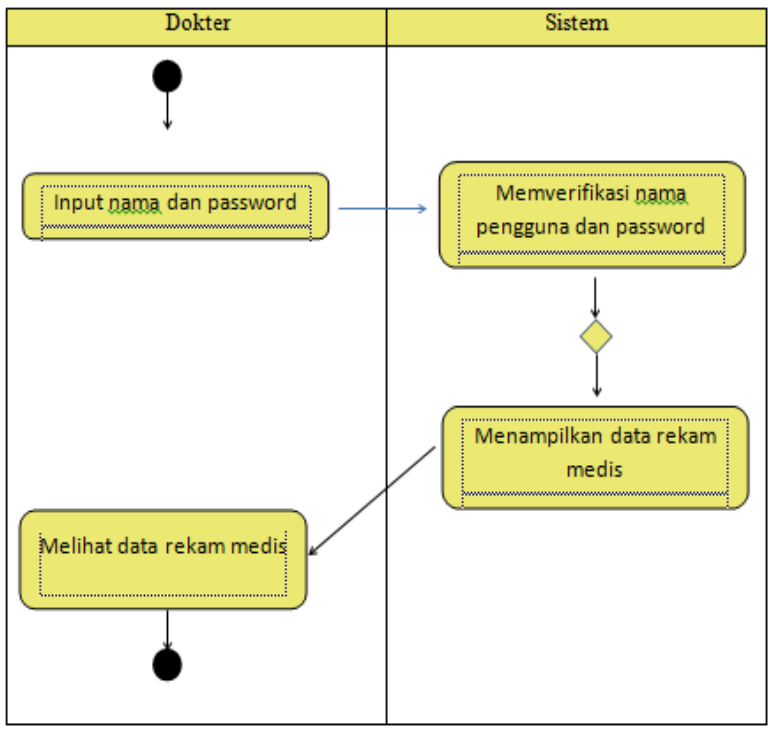

Gbr 3. Activity Diagram Dokter

Aktifitas diagram dokter berfungsi untuk menggambarkan alur proses interaksi dokter didalam system rekam medis ini, antara lain melihat data rekam medis atau riwayat berobat seseorang 


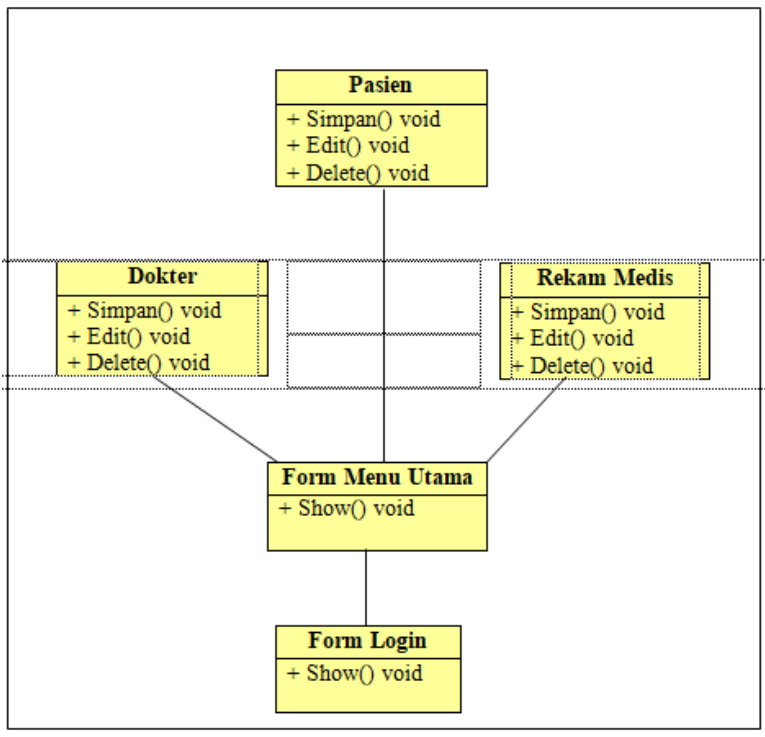

Gbr 4. Class Diagram

Class adalah sebuah spesifikasi yang jika diinstansi akan menghasilkan sebuah objek dan merupakan inti dari pengembangan dan desain berorientasi objek. Class mengambarkan keadaan (atribut/property) suatu system, sekaligus menawarkan layanan untuk memanipulasi keadaan tersebut (metode/fungsi).

\section{Implementasi Algoritma Boyer Moore}

Cara kerja algoritma turbo boyer moore ini adalah pertama : inisialisasi, karena algoritma ini menggunakan good suffix shift dan bad characters shift dari algoritma boyer moore maka untuk inisialisasi dijalankan prosedur preBmBc dan preBmGs seperti algoritma boyer moore. Kedua : melakukan proses pencocokan karakter pada pattern dengan karakter pada teks. Jika terjadi ketidak cocokan maka dilakukan pergeseran terbesar berdasarkan tabel $\mathrm{BmBc}$, table BmGs, dan turbo shift.

Pada fase pencarian kata dalam algoritma turbo boyer moore, proses yang dilakukan hamper sama dengan fase pencarian pada algoritma boyer moore, yang membedakan adalah adanya variable yang berfungsi untuk menampung nilai pergeseran apabila pada putaran sebelumnya nilai yang diambil untuk pergeseran berasal dari tabel good suffix shift. Nilai ini nantinya akan digunakan sebagai nilai yang mungkin digunakan untuk pergeseran pattern.

Berikut ini akan dijelaskan secara singkat cara pencarian pola pada Algoritma Turbo Boyer Moore,

Misalkan :

Teks : : L IS A P U T R I

Pattern : P U T R I
Pertama akan dilkukan perhitungan penilaian dengan tabel $\mathrm{BmBc}$ dan tabel BmGs. Cara menentukan nilai $\mathrm{BmBc}$ pada algoritma Turbo Boyer Moore :

Rumus $\mathrm{BmBc}=m-i-l$, dimana,

$m=$ panjang pola

$i=$ posisi index pada pola

\begin{tabular}{|c|c|c|c|c|c|}
\hline $\mathrm{I}$ & 0 & 1 & 2 & 3 & 4 \\
\hline $\mathrm{X}$ & $\mathrm{P}$ & $\mathrm{U}$ & $\mathrm{T}$ & $\mathrm{R}$ & $\mathrm{I}$ \\
\hline $\mathrm{BmBc}$ & 4 & 3 & 2 & 1 & 5 \\
\hline
\end{tabular}

Cara menentukan BmGs pada algoritma Turbo Boyer Moore :

Rumus BmGs $=$ BmGs $[(\mathrm{m}-1-\operatorname{suff}[\mathrm{i}])]=(\mathrm{im}-1-\mathrm{i})$ dimana,

$m=$ panjang pola

suff $[i]=$ posisi Suffix pada index pola

$i=$ posisi index pada pola

\begin{tabular}{|c|c|c|c|c|c|}
\hline $\mathrm{I}$ & 0 & 1 & 2 & 3 & 4 \\
\hline $\mathrm{X}$ & $\mathrm{P}$ & $\mathrm{U}$ & $\mathrm{T}$ & $\mathrm{R}$ & $\mathrm{I}$ \\
\hline Suff $[\mathrm{i}]$ & 0 & 0 & 0 & 0 & 5 \\
\hline BmGs & 4 & 4 & 4 & 4 & 1 \\
\hline
\end{tabular}

\begin{tabular}{|c|c|c|c|c|c|}
\hline $\mathrm{I}$ & 0 & 1 & 2 & 3 & 4 \\
\hline $\mathrm{x}[\mathrm{i}]$ & $\mathrm{P}$ & $\mathrm{U}$ & $\mathrm{T}$ & $\mathrm{R}$ & $\mathrm{I}$ \\
\hline Suff [i] & 0 & 0 & 0 & 0 & 5 \\
\hline BmGs [i] & 4 & 4 & 4 & 4 & 1 \\
\hline BmBc & 4 & 3 & 2 & 1 & 5 \\
\hline
\end{tabular}

Pencarian pola 1 :

\begin{tabular}{|c|c|c|c|c|c|c|c|c|c|c|}
\hline $\mathbf{E}$ & $\mathbf{L}$ & $\mathbf{I}$ & $\mathbf{S}$ & $\mathbf{A}$ & & $\mathbf{P}$ & $\mathbf{U}$ & $\mathbf{T}$ & $\mathbf{R}$ & $\mathbf{I}$ \\
\hline $\mathbf{P}$ & $\mathbf{U}$ & $\mathbf{T}$ & $\mathbf{R}$ & $\mathbf{I}$ & & & & & & \\
\hline
\end{tabular}

Pada pola pertama perbedaan didapatkan di index A, maka :

- BmGs [4] $=$ BmBc $[\mathrm{A}]-\mathrm{m}+($ index bawah +1$)$

BmGs $[4]=5-5+4=4$

- Shift by 4

- Sehingga geser pola sebanyak 4 ( nilai maksimal dari kedua perhitungan )

Pencarian pola 2 :

\begin{tabular}{|c|c|c|c|c|c|c|c|c|c|c|}
\hline $\mathbf{E}$ & $\mathbf{L}$ & $\mathbf{I}$ & $\mathbf{S}$ & $\mathbf{A}$ & & $\mathbf{P}$ & $\mathbf{U}$ & $\mathbf{T}$ & $\mathbf{R}$ & $\mathbf{I}$ \\
\hline & & & & $\mathbf{P}$ & $\mathbf{U}$ & $\mathbf{T}$ & $\mathbf{R}$ & $\mathbf{I}$ & & \\
\hline
\end{tabular}

Adanya perbedaan index $\mathrm{T}$, maka dilakukan perhitungan :

- Geser BmBc [T] $-\mathrm{m}+($ index bawah +1$)$

- BmGs [4] 2-5 + 4=1

- Sehingga geser pola sebanyak 4 ( nilai maksimal dari kedua perhitungan ) 
Pencarian pola 3 :

\begin{tabular}{|l|l|l|l|l|l|l|l|l|l|l|}
\hline $\mathbf{E}$ & $\mathbf{L}$ & $\mathbf{I}$ & $\mathbf{S}$ & $\mathbf{A}$ & & $\mathbf{P}$ & $\mathbf{U}$ & $\mathbf{T}$ & $\mathbf{R}$ & $\mathbf{I}$ \\
\hline & & & & & $\mathbf{P}$ & $\mathbf{U}$ & $\mathbf{T}$ & $\mathbf{R}$ & $\mathbf{I}$ & \\
\hline
\end{tabular}

Adanya perbedaan index $\mathrm{R}$, maka dilakukan Page | 264 perhitungan :

- Geser BmBc $[R]-m+($ index bawah +1$)$

- BmGs [4] 1-5 + 4=0

- Sehingga geser pola sebanyak 1 ( nilai maksimal dari kedua perhitungan )

Pencarian pola 4 :

\begin{tabular}{|l|l|l|l|l|l|l|l|l|l|l|}
\hline $\mathbf{E}$ & $\mathbf{L}$ & $\mathbf{I}$ & $\mathbf{S}$ & $\mathbf{A}$ & & $\mathbf{P}$ & $\mathbf{U}$ & $\mathbf{T}$ & $\mathbf{R}$ & $\mathbf{I}$ \\
\hline & & & & & & $\mathbf{P}$ & $\mathbf{U}$ & $\mathbf{T}$ & $\mathbf{R}$ & $\mathbf{I}$ \\
\hline
\end{tabular}

Pada pola keempat sudah mengalami kecocokan pada indeks terakhir.

\section{Aplikasi Rekam Medis}

Pada aplikasi ini terdapat 3 proses pencarian yaitu pencarian data obat, pencarian data dokter dan mpencarian data rekam medis pasien. Pada ketiga proses pencarian ini akan diterapkan algoritma Boyer Moore. Kode tersebut tersimpan pada file data pasien, data obat dan data dokter. Pattern tesk awal yang berasal dari objek form dimana langkah tersebut merupakan langkah awal di pencocokan awal algoritma turbo Boyer Moore. Selanjutnya algoritma ini berproses untuk mencocokan karakter perkarakter pattern dengan karakter pada tesk yang terdapat pada query sql antara tabel data pasien, tabel data rekam medis dengan tabel dokter.

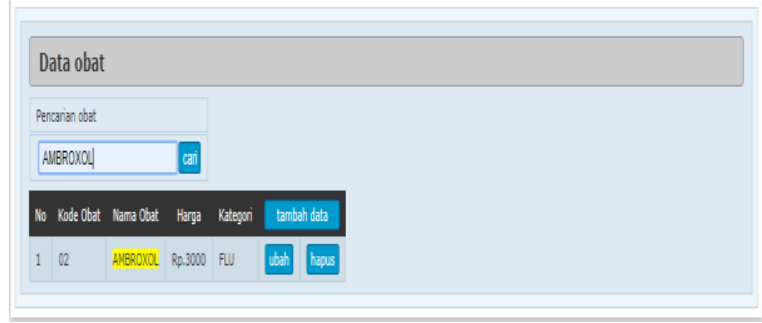

Gbr 5. Pencarian Boyer Moore Pada Data Obat

Gambar diatas menunjukan hasil pencarian pada data obat yang ada di puskesmas untuk mencari data dapat dilakukan dengan memasukan nama yang akan dicari pada menu cari yang ada di aplikasi rekam medis Nagaswidak. Dari mulai jenis obat hingga stok yang ada di puskesmas.

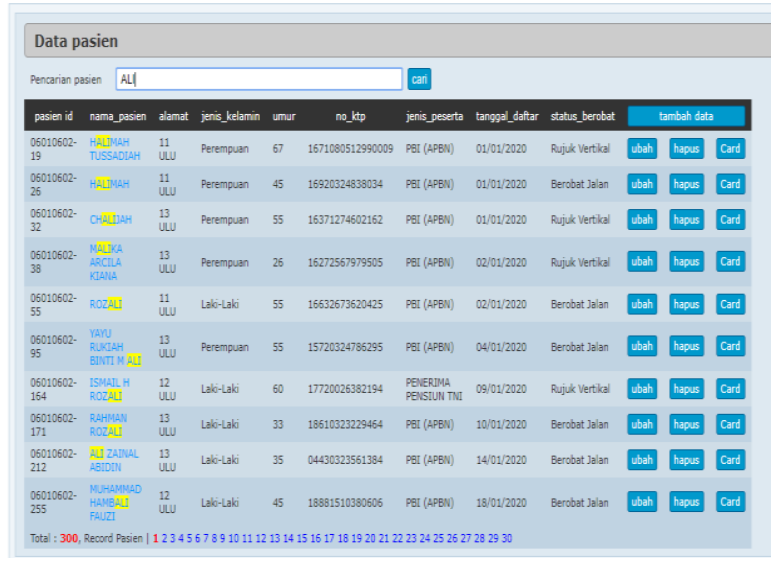

Gbr 6. Pencarian Boyer Moore Pada Data Pasien

Gambar diatas menunjukan hasil pencarian data pasien yang terdaftar di puskesmas Nagaswidak . dalam menu ini terdapat filed pasien id, nama pasien, alamat, jenis kelamin, usia, no ktp, jenis peserta, tanggal daftar serta status berobat.

Pada gambar 2 diberikan kata kunci 'Ali' maka akan menampilkan semua nama pasien yang mengandung kata 'ali', pada kasus ini di tampilkan nama '

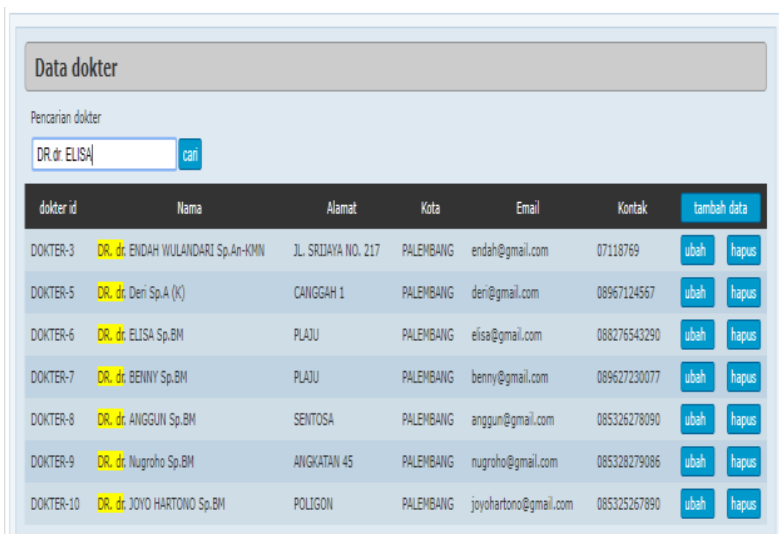

Gambar 7. Pencarian Boyer Moore Pada Data Dokter

Gambar diatas menunjukan hasil pencarian data dokter yang bertugas di puskesmas Nagaswidak, dari dokter sepesialis hingga dokter umum. 


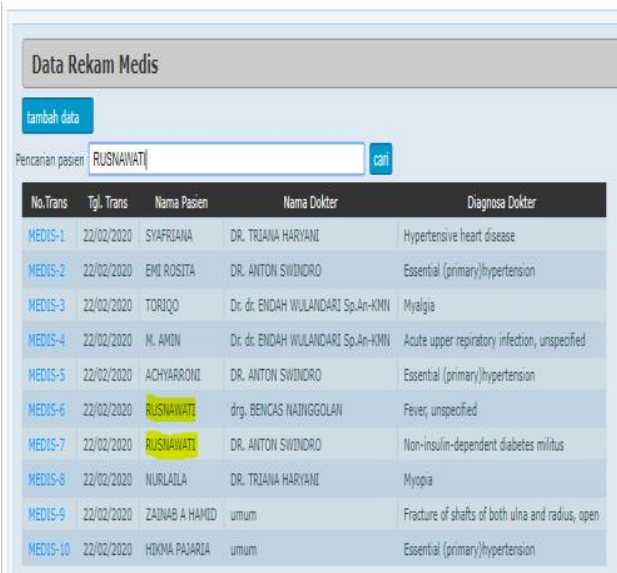

Gbr 8. Pencarian Boyer Moore Pada Rekam Medis Pasien

Gambar diatas terdapat hasil pencarian dari data rekam medis pasien puskesmas Nagaswidak, dimana menu ini dapat menampilkan kartu rekam medis pasien. Menu rekam medis terdiri dari nomor transaksi, tanggal transaksi, nama pasien, nama dokter dan diagnosis.

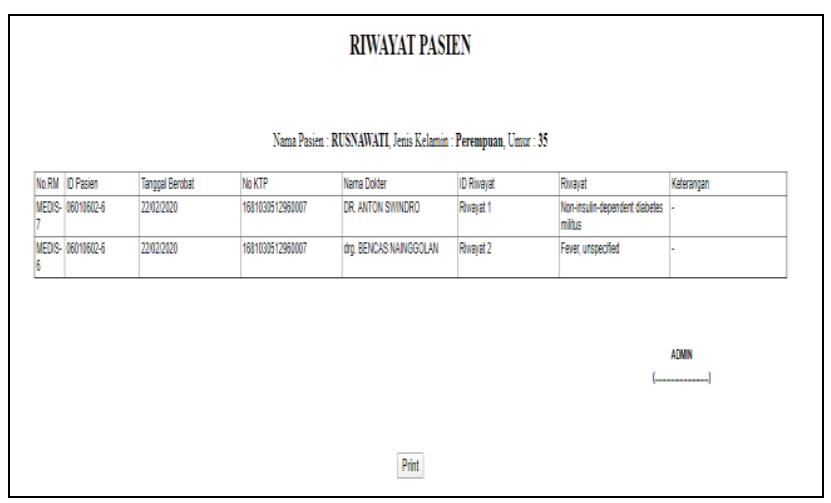

Gbr 9. Hasil Pencarian Rekam Medis Pasien

Hasil pencocokan string ditandai dengan text berwarna kuning. Pada pencarian selanjutnya tidak ada pergeseran pattern tesk yang diambil. Selanjutnya pencarian yang keluar adalah pencarian hanya dari proses query pada pungsi ajax yang ada, bukan di alogritma turbo booyer moore.

\section{E. Pengujian Aplikasi}

Pengujian keberhasilan algoritma Boyer Moore pada aplikasi rekam medis pasien dilakuan dengan melakukan 5 kali ujicoba dengan 5 variasi kata kunci.

TABEL I

HASIL UJI COBA ALGORITMA BOYER MOORE

\begin{tabular}{|c|c|c|c|c|}
\hline \multirow{2}{*}{ Kata } & \multicolumn{3}{|c|}{ Posisi Kata Kunci } & Kete- \\
\cline { 2 - 4 } Kunci & Awal & Tengah & Akhir & ranga \\
& Kata & Kata & Kata & $\mathrm{n}$ \\
\hline Ali & Ali & Chalijah & Rozali & Berha \\
& Zainal & & & sil \\
\hline
\end{tabular}

\begin{tabular}{|c|c|c|c|c|}
\hline Ana & Anawati & Sanah & Syafriana & $\begin{array}{c}\text { Berha } \\
\text { sil }\end{array}$ \\
\hline Rio & Rionaldi & $\begin{array}{c}\text { M. Rio } \\
\text { Saputra }\end{array}$ & $\begin{array}{c}\text { Rahmad } \\
\text { Rio }\end{array}$ & $\begin{array}{c}\text { Berha } \\
\text { sil }\end{array}$ \\
\hline Ria & Riandi & Fitriani & $\begin{array}{c}\text { Hika } \\
\text { Pajaria }\end{array}$ & $\begin{array}{c}\text { Berha } \\
\text { sil }\end{array}$ \\
\hline Nur & Nurmala & $\begin{array}{c}\text { Bella } \\
\text { Nur Aina }\end{array}$ & Izhar Nur & $\begin{array}{c}\text { Berha } \\
\text { sil }\end{array}$ \\
\hline
\end{tabular}

Analisis tingkat kemudahan dan tingkat kegunaan aplikasi rekam medis dilakukan dengan menyebarkan kuisioner pada 5 orang petugas filling.

TABEL II

UJICOBA KEMUDAHAN DAN KEGUNAAN APLIKASI

\begin{tabular}{|c|l|c|c|c|c|}
\hline \multirow{2}{*}{ No } & \multirow{2}{*}{ Nama Petugas } & \multicolumn{2}{c|}{$\begin{array}{c}\text { Tingkat } \\
\text { Kemudahan }\end{array}$} & \multicolumn{2}{c|}{$\begin{array}{c}\text { Tingkat } \\
\text { Kegunaan }\end{array}$} \\
\cline { 3 - 6 } & & Ya & Tidak & Ya & Tidak \\
\hline 1 & Ida Royani & $\sqrt{ }$ & - & $\sqrt{ }$ & - \\
\hline 2 & dr. Ice Rahmawati & - & - & $\sqrt{ }$ & - \\
\hline 3 & Ners. Rully S.Kep & $\sqrt{ }$ & - & $\sqrt{ }$ & - \\
\hline 4 & Rani Widya S.Kep & $\sqrt{ }$ & - & $\sqrt{ }$ & - \\
\hline 5 & Angelia S.Kep & $\sqrt{ }$ & - & $\sqrt{ }$ & - \\
\hline
\end{tabular}

\section{KESIMPULAN}

Berdasarkan pembahasan diatas diambil kesimpulan bahwa

1) Algoritma Boyer Moore dapat melakukan pencarian di awal kata, tengah kata dan akhir kata berdasarkan pada kata kunci yang diberikan. Berdasarkan 5 kali uji coba yang dilakukan diperoleh tingkat keberhasilan yang tinggi yakni $100 \%$.

2) Dalam hasil quisioner yang disebarkan kepada 5 orang petugas fiiling, didapatkan bahwa tingkat kemudahan dan tingkat kegunaan aplikasi rekam medis dengan menggunakan algoritma Boyer Moore didapatkan hasil bahwa tingkat kemudahan yaitu $80 \%$ dan tingkat kegunaan $100 \%$.

\section{DAFTAR PUSTAKA}

[1] A. Fau, 'Analisa Perbandingan Boyer Moore Dan Knuth Morris Pratt Dalam Pencarian Judul Buku Menerapkan Metode Perbandingan Eksponensial', no. 1, p. 12, 2017.

[2] F. H. Harahap, 'PENERAPAN ALGORITMA TURBO BOOYERMOORE DALAM PENCARIAN REKAM MEDIS PASIEN PADA RS. BUNDA THAMRIN', vol. 18, p. 4, 2019.

[3] K. W. Argakusumah and S. Hansun, 'Implementasi Algoritma Boyer-Moore pada Aplikasi Kamus Kedokteran Berbasis Android', p. 9.

[4] E. Rahmanita, 'PENCARIAN STRING MENGGUNAKAN ALGORITMA BOYER MOORE PADA DOKUMEN', vol. 1, no. 1, p. 12, 2014. 
[5] S. M. Panjaitan, C. Simbolon, and E. Siahaan, 'Penerapan Algoritma Turbo Boyer Moore Dalam Pencarian Judul Lagu Rohani Pada Puji Syukur Berbasis Android', p. 5, 2019.

[6] R. I. Borman and A. Pratama, 'PENERAPAN STRING MATCHING DENGAN ALGORITMA BOYER MOORE PADA APLIKASI FONT ITALIC UNTUK DETEKSI KATA ASING', . ISSN, vol. 10, no. 2, p. 5, 2016.

Page | 266 [7] D. Effendi, T. Hartono, and A. Kurnaedi, 'PENERAPAN STRING MATCHING MENGGUNAKAN ALGORITMA BOYER-MOORE PADA TRANSLATOR BAHASA PASCAL KE C', no. 2, p. 14.

[8] R. I. Darmawan and A. H. Setianingrum, 'Implementasi Algoritma Boyer Moore Pada Aplikasi Kamus Istilah Kebidanan Berbasis Web', J. Sist. Inf., vol. 02, no. 01, p. 10, 2018.

[9] Pedoman Penyelenggaraan Rekam Medis RS 2.pdf'.

[10] C. Charras and T. Lecroq, 'Handbook of Exact StringMatching Algorithms', p. 220.

[11] S. Farlinda, R. Nurul, and S. A. Rahmadani, 'Pembuatan Aplikasi Filling Rekam Medis Rumah Sakit', p. 6.

[12] A. Firman, H. F. Wowor, and X. Najoan, 'Sistem Informasi Perpustakaan Online Berbasis Web', p. 8, 2016.

[13] Raharjo, 'Pengertian MySQL', 2011.

[14] Nugroho, 'Pengeertian UML (Unified Modeling Language)', 2016. 